\title{
Penerapan Metode User Centered Design dalam Menganalisis User Interface pada Website Universitas Sriwijaya
}

\author{
Ikhda Uswatun Khasanah ${ }^{1}$, Muammar Fachry ${ }^{2}$, Nadia Saphira Adriani ${ }^{3}$, Nanda Defiani ${ }^{4}$, Yopis \\ Saputra $^{5}$, Ali Ibrahim ${ }^{6}$ \\ Program Studi Sistem Informasi, Fakultas Ilmu Komputer, Universitas Sriwijaya \\ Email: 'ikhda.uh17@gmail.com, ${ }^{2}$ muammarfachry@gmail.com, \\ 3nadiasaphiraa@gmail.com, ${ }^{4}$ nandadefiani@gmail.com, ${ }^{5}$ yopisaputra12@gmail.com; \\ 6aliibrahimok@gmail.com
}

\begin{abstract}
Website is an integrated media delivery of information provided through the Internet network so that it can be accessed by anyone and anywhere very easily. The utilization of the website not only in small and large commercial companies but also in educational institutions in this case is the University of Sriwijaya, its own website has been very rapidly growing from User Interface sessions to feature features provided which progressively grows to follow the needs of the User. In this study the authors conducted an analysis on the Website of Sriwijaya University to measure the feasibility of User Interface on the website by using UCD method (User centered Design). UCD is a user interface design process that focuses on interface, accessibility, and Usefulness in user interface design that involves the user as the center of the process by providing input or assessment in the form of questionnaire. The final result of this study is the User Interface assessment of the UNSRI website (Sriwijaya University) conducted by the user. And from the results of this study found that $43.8 \%$ of students expressed satisfaction on the Interface of the UNSRI's website.
\end{abstract}

Keywords: UCD, User Interface, User Centered Design, website.

\begin{abstract}
Abstrak Website merupakan suatu media penyampaian informasi terintegrasi yang disediakan melalui jaringan internet sehingga dapat diakses oleh siapapun dan dimanapun dengan sangat mudah. Pemanfaatan website tidak hanya pada perusahaan komersil kecil hinggga besar namun juga pada institusi pendidikan dalam hal ini adalah Universitas Sriwijaya, website sendiri saat ini telah sangat berkembang pesat mulai dari sesi User Interface hingga fitur fitur yang disediakan yang semakin hari semakin berkembang mengikuti kebutuhan User. Dalam penelitian ini penulis melakukan analisis pada Website Universitas Sriwijaya untuk mengukur kelayakan User Interface pada website tersebut dengan menggunakan metode UCD(User centered Design). UCD merupakan suatu proses desain user interface yang berfokus pada interface, accessibility, dan Usefulnes dalam desain user interface yang melibatkan pengguna(user) sebagai pusat dari proses dengan memberikan masukan atau penilaian dalam bentuk kuesioner. Hasil akhir dari penelitian ini adalah penilaian User Interface dari website UNSRI(Universitas Sriwijaya) yang dilakukan oleh user. Dan dari hasil penelitian ini diketahui bahwa 43,8\% mahasiswa menyatakan puas terhadap Interface dari website UNSRI.
\end{abstract}

Kata Kunci : UCD, User Interface, User Centered Design, website.

\section{Pendahuluan}

Internet merupakan salah satu kemajuan dalam bidang teknologi yang paling pesat saat ini. Tak asing lagi bagi kalangan masyarakat bahwa internet menjadi satu dari kebutuhan penting dalam rutinitas, Terutama pada fungsinya terhadap pertukaran informasi. Sehingga semua kalangan masyarakat dapat mengetahui informasi apa saja dengan cara menjelajahi internet. Seperti kita ketahui, pemanfaatan internet tak lepas dari jasa sebuah layanan website yang merupakan tempat bagi user untuk mendapatkan 
informasi yang dibutuhkan. Tampil menarik, komunikatif, dan user friendly yang menjadi salah satu sarana untuk menarik user agar mengunjungi website.

Sebuah website menjadi peranan besar di semua perusahan dan institusi pendidikan, khususnya Universitas Sriwijaya Palembang. Alasan universitas sriwijaya menghadirkan sebuah website agar dapat mepromosikan dan menyampaikan informasikan yang diperlukan masyarakat. Oleh karena itu perusahaan maupun institusi di tuntut untuk menciptakan dan memikirkan inovasi - inovasi baru agar dapat bersaing dan bertahan dalam dunia bisnis pendidikan yang ketat ini.

Dari pernyataan diatas user interface website Universitas Sriwijaya diperlukan analisis secara detail untuk mengukur tingkat kemudahan penggunaan, kepuasaan, dan keefisienan sebuah website yang merupakan tolak ukur keberlangsungan dan pengembangan untuk kedepan. Metode yang akan digunakan untuk menganalisis user interface adalah metode User Centered Design.

Metode User Centered Design (UCD) adalah paradigma baru dalam pengembangan sistem berbasis web. Perancangan berbasis user adalah istilah yang digunakan untuk menggambarkan filosofi perancangan. Konsep dari UCD adalah user sebagai pusat dari proses pengembangan sistem, dan tujuan atau sifat - sifat, konteks dan lingkungan semua sistem.

\section{Metode}

Metode pengumpulan data dan penelitian yang digunakan adalah sebagai berikut :

\subsection{Metode Pengumpulan Data}

Data yang akan dianalaisis didapat melalui

1. Studi Literatur

Tahap ini dilakukan dengan mengumpulkan, membaca dan memahami beberapa referensi referensi yang berkaitan dengan penelitian yaitu melalui jurnal, buku, artikel dan lain-lain.

2. Kuisioner

Kuisioner merupakan metode pengumpulan data dengan cara memberikan pertanyaan kepada beberapa responden yang digunakan untuk mengevaluasi dan menggali kebutuhan sistem. Adapun kuisioner ini bersifat tertutup dengan jumlah sample 30 responden.

\subsection{Metode Penelitian}

Dalam penelitian ini, metode yang digunakan adalah UCD (User Centered Design). Henry, S. L. (2004) menyatakan bahwa User Centered Design adalah sebuah proses desain interface (antarmuka) yang fokus terhadap tujuan kegunaan, karakteristik pengguna, lingkungan, tugas, dan alur kerja di dalam desainnya. L. Albani and G. Lombardi (2010) mengklasifikasikan proses metode UCD dalam lima tahapan, yaitu :

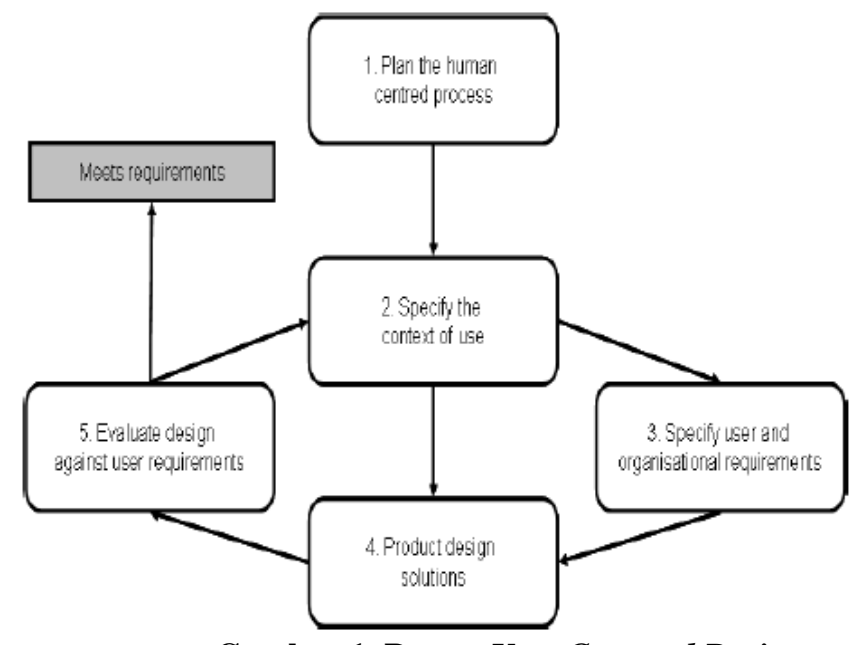

Gambar 1. Proses User Centered Design

(L. Albani and G. Lombardi (2010) ) 
Pada tahap awal ini, peneliti melakukan diskusi yang berfokus pada komitmen bahwa proyek berpusat pada pengguna atau user. Tahap kedua, dilakukan identifikasi pengguna terhadap kondsi penggunaan produk yang dalam penelitian ini berupa website. Tahap ketiga, spesifikasi kebutuhan baik dari kebutuhan pengguna ataupun kebutuhan organisasi. Tahap keempat, memberikan solusi dari produk yang sedang dianalisis dengan merancang design. Tahap kelima, evaluasi design.

\section{Hasil dan Pembahasan}

\section{1 tudi Literatur}

Pada tahap ini dilakukan pengumpulan data-data yang di butuhkan seperti pendapat mahasiswamahasiswa universitas sriwijaya terhadap website unsri.ac.id yaitu melalui kuisioner online.

\subsubsection{Menentukan Pertanyaan}

Pada tahap ini akan ditentukan konsep pertanyaan yang akan ditanyakan terhadap mahasiswamahasiswa unsri. Dimana ada 9 tahapan yaitu : Efficiency and Effectiveness, Productivity, Satisfication, Learnability, Safety, Trustfulness, Accesibility, Universality, Usefulness.

\subsubsection{Memberikan Pertanyaan}

Tahapan ini merupakan pengimplementasian dari tahap sebelumnya. Dimana pada tahapan ini akan memberikan pertanyaan kepada mahasiswa unsri melalui google form yang dilakukan secara online.

\subsubsection{Persentase Hasil Pertanyaan}

Pada tahap ini akan di dapat hasil dari pertanyaan yang diajukan kepada mahasiswa unsri sebagai berikut :

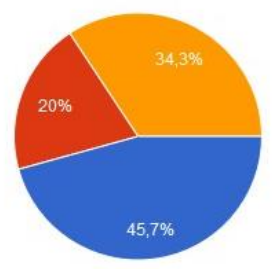

Gambar 2. Segi Efisien dan Efiektif
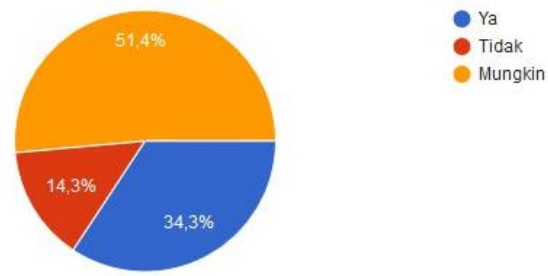

Gambar 3. Segi Fitur dan Informasi
Pada diagram 2, dari segi efisien dan efektif responden menyatakan:

- $\quad 45,7 \%$ menyatakan ya

- $\quad 34,3$ menyatakan mungkin

- $\quad$ Dan 20\% menyatakan tidak

Pada diagram 3, dari segi fitur dan informasi responden menyatakan:

- $\quad 34,3 \%$ menyatakan ya

- $\quad 51,4 \%$ menyatakan mungkin

- $\quad$ Dan $14,3 \%$ menyatakan tidak 


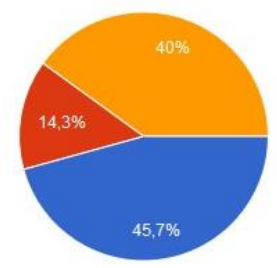

Gambar 4. Segi Kegunaan Informasi

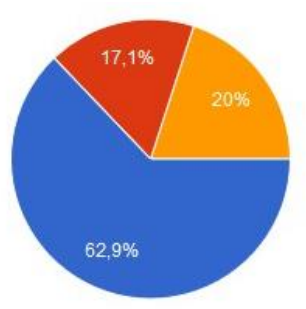

Gambar 5. Segi User Friendly

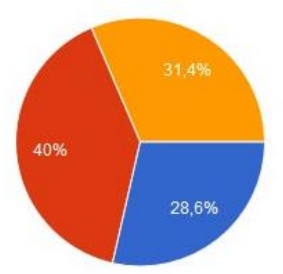

Gambar 6. Segi Desain
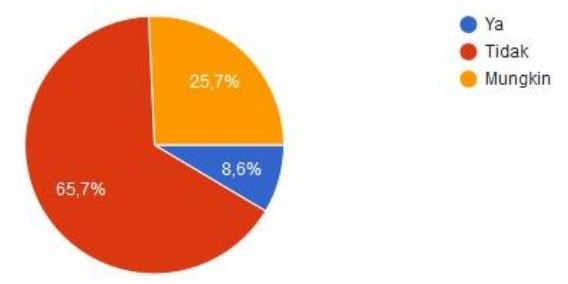

Gambar 7. Segi Kecepatan Akses
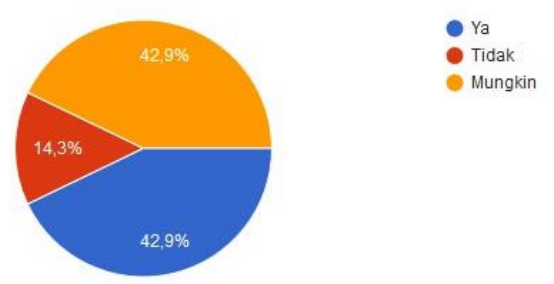

Gambar 8. Segi Kemudahan dalam Pencarian
Pada diagram 4, dari segi kegunaan informasi responden menyatakan:

- $\quad 45,7 \%$ menyatakan ya

- $\quad 40 \%$ menyatakan mungkin

- Dan 14,3\% menyatakan tidak

Pada diagram 5, dari segi user friendly responden menyatakan:

- $\quad 62,9 \%$ menyatakan ya

- $\quad 20 \%$ menyatakan mungkin

- $\quad$ Dan $17,1 \%$ menyatakan tidak

Pada diagram 6, dari segi desain responden menyatakan:

- $\quad 28,6 \%$ menyatakan ya

- $\quad 31,4 \%$ menyatakan mungkin

- Dan $40 \%$ menyatakan tidak

Pada diagram 7, dari segi kecepatan akses responden menyatakan:

- $\quad 8,6 \%$ menyatakan ya

- $\quad 25,7 \%$ menyatakan mungkin

- Dan 65,7\% menyatakan tidak

Pada diagram 8 , dari segi kemudahan dalam pencarian responden menyatakan:

- $\quad 42,9 \%$ menyatakan ya

- $\quad 42,8 \%$ menyatakan mungkin

- Dan 14,3\% menyatakan tidak 


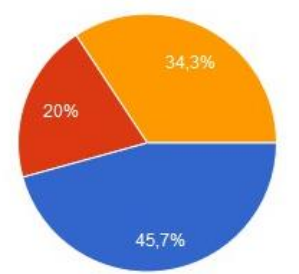

Gambar 9. Segi Keamanan Informasi
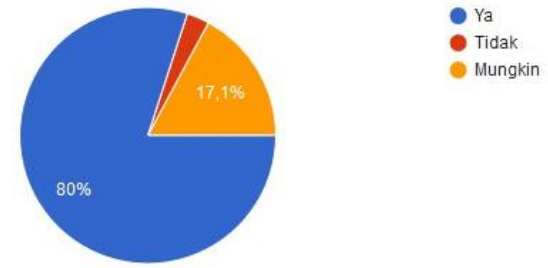

Pada diagram 9, dari segi keamanan informasi responden menyatakan:

- $\quad 45,7 \%$ menyatakan ya

- $\quad 34,3 \%$ menyatakan mungkin

- $\quad$ Dan 20\% menyatakan tidak

Gambar 10. Segi Kemudahan dalam Mengakses

\subsection{Analisis Hasil}

Dari hasil sebelumnya akan didapat kesimpulan mengenai website unsri.ac.id seperti diagram dibawah ini :

$$
\begin{aligned}
& \text { Pada diagram 10, dari segi kemudahan dalam } \\
& \text { mengakses responden menyatakan: } \\
& \text { - } 80 \% \text { menyatakan ya } \\
& \text { - } \quad 17,1 \% \text { menyatakan mungkin } \\
& \text { - } \quad \text { Dan } 2,9 \% \text { menyatakan tidak }
\end{aligned}
$$

\section{$\Rightarrow$ Frequencies}

$$
\text { [Dataset2] }
$$

\begin{tabular}{|ll|r|r|r|}
\hline & \multicolumn{1}{|c|}{ Statistics } \\
\hline $\mathrm{N}$ & Valid & 9 & mungkin & \multicolumn{1}{c|}{ tidak } \\
& Missing & 0 & 0 & 9 \\
Mean & 43.6222 & 33.0111 & 23.1778 \\
Median & 45.7000 & 34.3000 & 17.1000 \\
Sum & 392.60 & 297.10 & 208.60 \\
\hline
\end{tabular}

\section{Gambar 11. Pesentase Tingkat Kepuasan}

Dari table diatas meskipun mahasiswa cukup puas dengan website unsri sekarang namun banyak juga mahasiswa yang masih ragu akan website unsri saat ini begitu juga persentase ketidakpuasan yang masih cukup besar dengan persentase $23,2 \%$.

\section{Kesimpulan}

Berdasarkan hasil analisis kepuasan mahasiswa terhadap website unsri.ac.id yang dilakukan secara online dapat kita simpulkan bahwa website tersebut masih butuh perbaikan, hal ini dapat dilihat dari persentase tingkat kepuasan dimana yang merasa puas itu sebanyak $43,8 \%$, yang memilih mungkin/masih bingung sebesar 33\% dan yang memilih tidak sebesar 23,2\%. Dari pesentase itu dapat kita lihat bahwa tingkat kepuasan masih rendah karena masih di bawah $50 \%$.

Berdasarkan analisis yang dilakukan, maka penganalisis dapat menyarankan perusahaan/lembaga untuk perlu meningkatkan pengawasan dan pengendalian mutu produk secara kontinu terutama dalam hal interface, accessibility, dan Usefulness. 


\section{Referensi}

Akay, Y. V., Santoso, A. J., \& Rahayu, S. F. (2017). Metode User Centered Design (UCD) Dalam Perancangan Sistem Informasi Geografis Pemetaan Tindak Kriminalitas (Studi Kasus : Kota Manado).

Bahari, F. M., Effendy, V., \& Jatmiko, D. D. (2017). Model User Experience Aplikasi Pembelajaran Anatomi Tubuh Manusia Untuk Anak Kelas 5 SD dengan Teknologi Augmented Reality menggunakan Metode User Centered Design. e-Proceeding of Engineering Vol. 4 No. 3 .

Fajrin, M. H., Effendy, V., \& Jatmiko, D. D. (2017). Analisis dan Implementasi User Interface Aplikasi Media Pembelajaran Interaktif Sistem Tata Surya untuk PAUD dengan Teknologi Augmented Reality (AR) Menggunakan Metode User Centered Design. e-Proceeding of Engineering Vol. 4 No. 3 .

Hariyady. (2017). Pembangunan Aplikasi Mobile "Green and Clean UMM" menggunakan Metode User Centered Design.

Kartiningrum, E. D. (2015). Panduan Penyusunan Studi Literatur. 5.

Riyadi, A. S., Retnandi, E., \& Deddy, A. (2012). Perancangan Sistem Informasi Berbasis Website Subsistem Guru di Sekolah Pesantren Persatuan Islam 99 Rancabango. Jurnal Algoritma , 3.

Pujihastuti, I. (2010). Prinsip Penulisan Kuisioner Penelitian. Jurnal Agribisnis dan Pengembangan Wilayah Vol. 2 No. 1 , 44.

Saputri, I. S., Fadhli, M., \& Surya, I. (2017). Penerapan Metode UCD (User Centered Design) pada ECommerce Putri Intan Shop Berbasis Web. Jurnal Teknologi dan Sistem Informasi Vol. 3 No. 2

Shidqi, L. L., Effendy, V., \& Herdiani, A. (2017). Model Usel Interface Aplikasi Pembelajaran Doa-doa Harian Sesuai User Experience Anak Usia Dini Menggunakan Metode User Centered Design. Jurnal e-Proceeding of Engineering Vol. 4 No. 3 .

Utomo, S. D., Effendy, V., \& Jatmiko, D. D. (2017). Analisis Dan Implementasi User Interface Aplikasi Pengenalan Hewan Sebagai Media Interaktif Pembelajaran Untuk Pendidikan Anak Usia Dini Dengan Teknologi Augmented Reality Menggunakan Metode Child Centered Design Jurnal Tugas Akhir Universitas Telkom. e-Proceeding of Engineering Vol. 4 No. 3 .

Yumarlin, M. (2016). Evaluasi Penggunaan Website Universitas JANABADRA dengan menggunakan metode Usability Testing. Jurnal Informasi Interaktif Vol. 1 No. 2 . 
Khasanah, Penerapan Metode User Centered Design dalam Menganalisis User Interface pada Website Universitas Sriwijaya 27

Halaman ini sengaja dikosongkan 